\title{
Non-Destructive Investigation of Pre-Columbian Goldwork from Panama with Variable Pressure Scanning Electron Microscopy
}

\author{
A.C. Harrison, ${ }^{*}$ H.F. Beaubien, ${ }^{* *}$ and K. Cullen Cobb, ${ }^{* *}$ \\ * National Museum of the American Indian, Smithsonian Institution, CRC 4220 Silver Hill \\ Road, Suitland MD, 20746 \\ ** Museum Conservation Institute, Smithsonian Institution, 4210 Silver Hill Road, Suitland MD, \\ 20746
}

The Smithsonian's holdings of Pre-Columbian gold alloy objects from Panama were examined and analyzed using optical microscopy and a variety of non-destructive instrumental techniques including $\mathrm{x}$-ray fluorescence analysis (XRF) and variable pressure scanning electron microscopy with energy dispersive spectroscopy (VP-SEM-EDS). The 309 objects in the collections of the National Museum of the American Indian (NMAI) and National Museum of Natural History (NMNH), as well as nine objects brought back from recent excavations in Panama, underwent analysis as part of a research project at the Smithsonian's Museum Conservation Institute (MCI) to investigate the technology of goldworking in ancient Panama.

Goldworking technology spread to Panama from neighboring regions in the first centuries AD; however, not all metalworking techniques were adopted and many stylistic and technological variations developed locally [1]. Almost all of the objects examined in this study were fabricated from $\mathrm{Au}-\mathrm{Ag}-\mathrm{Cu}$ alloys and include: pendants, plaques, nose rings, finger rings, ear rods, bands, cuffs, sheathing, beads, and tools.

Optical microscopy alone was capable of providing a great deal of technological information such as primary fabrication method (e.g. cast vs. hammered), as well as some joining and finishing techniques. Examination of every object in the study was therefore carried out under the stereomicroscope while evidence of manufacture was recorded with photomicrographs and entered into the project database.

In cases where the methods of fabrication and joining remained unclear from examination under the microscope, objects were selected to undergo VP-SEM-EDS. As only non-destructive analysis was permitted on the Smithsonian material, this technique was ideal to help answer research questions not resolved with optical microscopy or XRF. Whole objects were placed in the sample chamber without any additional sample preparation and were analyzed at full-vacuum or in variable pressure mode depending on the object and presence of polymer coatings from conservation treatments. Imaging of objects was performed with a Hitachi S-3700N VP-SEM and elemental mapping was carried out with a Bruker EDS. All objects were analyzed at $15 \mathrm{keV}$ at $10-15 \mathrm{~mm}$ working distance.

Despite the limitations of non-destructive and purely qualitative analysis, the high magnification imaging and elemental mapping provided by VP-SEM-EDS were effective in characterizing individual objects. This in turn allowed documentation of the wide range of goldworking technologies used in ancient Panama. For example, dendritic structures from casting were clearly visible in SEM images and coring was distinguishable through elemental mapping (fig.1). 
Surface finishing and enrichment techniques, such as depletion gilding were also distinguishable on objects with exposed break edges (fig.2).

Also of note were a group of gold-alloy fishhooks fabricated by a number of different methods. SEM imaging revealed tool-marks from a drawplate on one of the hooks, which is of particular interest as no Pre-Columbian drawplate or drawn wire has been previously identified in Panama (fig.3). Elemental mapping of the fishhooks and several other objects, including a finger ring and cast tubular bead, revealed the use of Ag solder as a repair technique. Solder has rarely been identified on Panamanian objects; however, and the question therefore remains as to whether these are modern or ancient repairs. Other joining techniques were examined using elemental mapping, such as those used in the manufacture of small circular beads. The majority beads were found to have been formed from hammered sheet and joined without the use of solder or eutectic bonding (fig.4). Results from a technical study of the gold beads are forthcoming [2]. All of the VP-SEM-EDS data gathered on the objects in this study are archived at the Smithsonian and are available to those researching and conserving pre-Columbian gold at the Smithsonian and elsewhere [3].

\section{References}

[1] R.G.Cooke et al., Contextualized goldwork from 'Gran Cocle,' Panama, in PreColumbian Gold: Technology, Style and Iconography, British Museum, London, 2002, 154.

[2] A.C.Harrison et al., A Study of Pre-Columbian Gold Beads from Panama, in SEM and Microanalysis in the Study of Historical Technology, Materials and Conservation, Archetype, London, 2011 (In Review).

[3] This research was supported by Fellowships funded by the Kress and Mellon Foundations. The aid of Judy Watson as SEM technician is gratefully acknowledged.
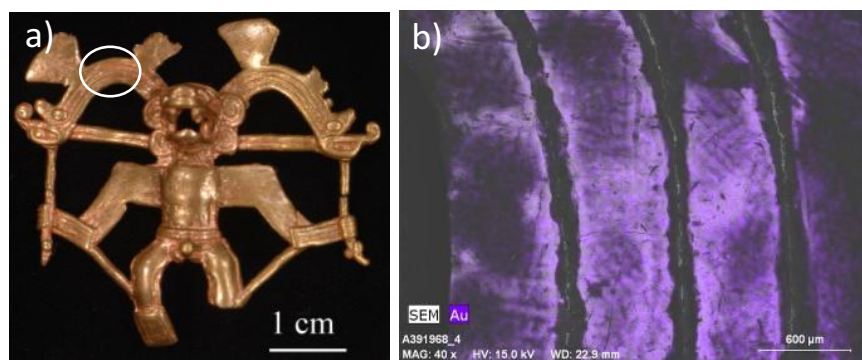

FIG.1 a) Jaguar pendant A391968, NMNH

b) Map of Au distribution showing dendritic pattern.
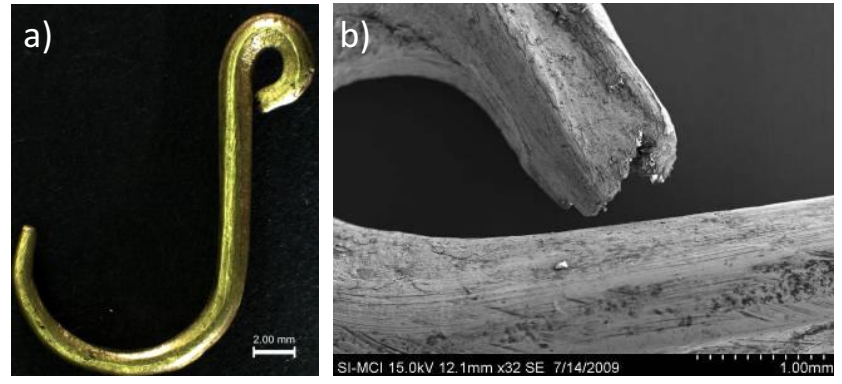

FIG.3 (a) Fishhook 240651.000, NMAI (b) SEM image showing linear striations on fishhook possibly from a drawplate.
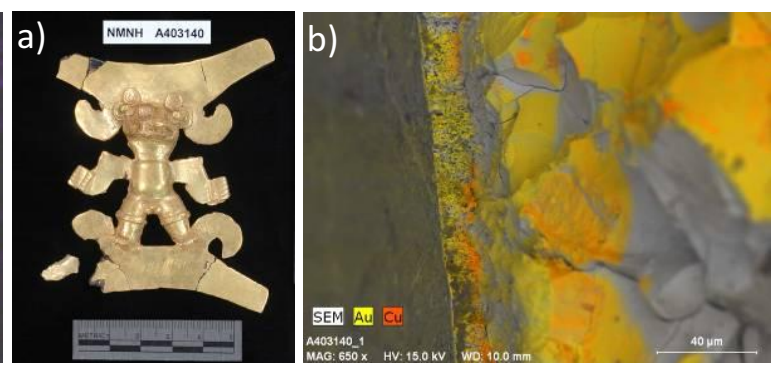

FIG.2 a) Pendant A403140, NMNH b) Elemental map of break edge showing enriched surface layer.

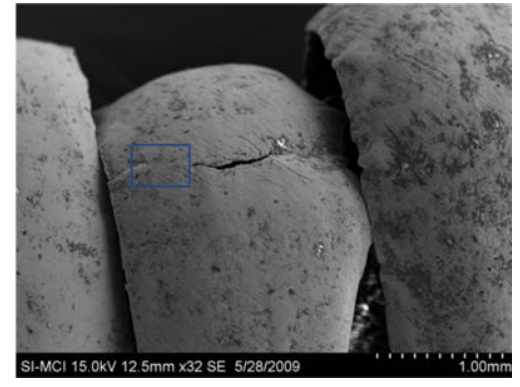

FIG.4 SEM image of a circular bead A396672 (NMNH) showing a join achieved without solder. 